DOI: $10.30519 /$ ahtr. 801690

Advances in Hospitality and Tourism Research (AHTR)

\title{
ARTIFICIAL INTELLIGENCE IN TOURISM: A REVIEW AND BIBLIOMETRICS RESEARCH
}

\author{
İsmail Gökay KIRTIL ${ }^{1}$ \\ Demre Dr. Hasan Ünal Vocational School, Akdeniz University, Turkey \\ ORCID: 0000-0002-3520-9600 \\ Volkan AŞKUN \\ Demre Dr. Hasan Ünal Vocational School, Akdeniz University, Turkey \\ ORCID: 0000-0003-2746-502X
}

\begin{abstract}
Artificial Intelligence (AI) came up as an ambiguous concept from computer sciences and now it is being used in many areas of our life. It has stimulated academia's interest due to its alternative insights into complex problems. Therefore, a bibliometric method was applied in this study to observe the progress of $\mathrm{AI}$ in the tourism field. A total of 102 papers were collected from Scopus database. Key factors such as most productive authors, collaborations and institutions were identified, and research hotspots were determined using co-occurrence network and most common author keywords. Progress of AI was visualized with thematic evolution analysis. Findings indicate that there is a progressive interest in AI after 2017, and average citations signify that papers are highly cited. Since this is the first study conducting a bibliometric on $\mathrm{AI}$ in the tourism context, it could be considered useful for academics and tourism professionals as it provides general overview of $\mathrm{AI}$, demonstrates research trends and popular papers.
\end{abstract}

Article History

Received 29 September 2020

Revised 9 December 2020

Accepted 21 December 2020

Available online 22 Feb. 2021

\section{Keywords}

bibliometric

artificial intelligence

hospitality and tourism

co-citation analysis

co-occurrence analysis

thematic analysis

\section{INTRODUCTION}

"I believe there is no deep difference between what can be achieved by a biological brain and what can be achieved by a computer. It therefore follows that computers can, in theory, emulate human intelligence, and exceed it." Stephen Hawking

Information and Communication Technologies (ICTs) in tourism, also known as e-tourism concept, started a new era in contemporary tourism

\footnotetext{
${ }^{1}$ Address correspondence to İsmail Gökay Kırtıl, Demre Dr. Hasan Ünal Vocational School, Akdeniz University, Antalya, Turkey. E-mail: gokay@akdeniz.edu.tr
} 
and hospitality industry. ICTs enabled researchers to assess tourist behavior through intelligent systems much faster and allowed them to deal with large amount of data coming from both tourists and destination parties. ICTs also affected tourist behavior radically (Buhalis, 2003) by changing the way tourists consume, purchase, and share their experiences (Gretzel et al., 2006). Tourists and service providers had the chance to access relevant information more accurately, with increased mobility and a greater decision-making process, eventually, acquiring a more favorable tourism experience (Gretzel, 2011).

In consideration of advances in ICTs, Artificial Intelligence (AI) is regarded as the next stage of tourism industry (Bowen \& Whalen, 2017; Gajdošík \& Marciš, 2019; Kazak et al., 2020). AI is known for its sophisticated computing capabilities as it can deal with complex relations and problems among different concepts (Pannu, 2015) and can easily work with a big amount of data (Inanc-Demir \& Kozak, 2019). Broadly speaking, an AI system senses external information, understands these, acts in turn to achieve given goals and learns from its own experiences (Ferràs et al., 2020). AI functions similar to a human brain as it thinks, learns, makes decisions and inferences through given data by using intelligent machines. The main purpose of AI is to enable machines to complete tasks automatically without needing a human brain (Singh et al, 2020).

Since the late 1990s, AI studies have been applied in tourism researches to forecast hotel occupancy and tourism demand (Law, 1998, 2000). Afterwards, researchers used AI in different kind of inquiries such as resource management in tourism companies (Casteleiro-Roca et al., 2018), examining social media data and online reviews (Kirilenko et al., 2018; Topal \& Uçar, 2018), forecasting tourist flow and arrivals (Zhang et al., 2020), evaluating tourist satisfaction through facial expression recognition (González-Rodríguez et al., 2020), and making smart recommendations (Zheng et al., 2020). AI models are used in tourism studies increasingly because these models have much more flexibility and they can be used to estimate non-linear relationships without the limits of traditional methods (Hadavandi et al., 2011).

Although AI promises entirely alternative solutions for potential and prospective issues of tourism, with its advanced computing and problemsolving abilities, there is a lack of academic research on AI in context of tourism (Gajdošík \& Marciš, 2019; Zlatanov \& Popesku, 2019). Therefore, this study adopted a bibliometric method to evaluate the progress, research themes, and statistical data of AI in tourism field within the scope of data 
gathered from Scopus database. In line with this purpose, main objectives of this study are to:

- Provide an expanded overview of AI,

- Explore the overall theoretical foundation and progress of AI research in tourism field by focusing on leading contributors (authors, keywords, publications, and institutions),

- Visualize above-mentioned metrics and the evolution of AI, and

- Suggest a future research agenda for tourism academicians and practitioners.

The findings of this study have several useful implications. For social scientists and tourism researchers interested in AI, the study indicates an overview of the subject in concern with key studies, authors, collaborations, and emerging topics. As an emerging and interdisciplinary field, AI can provide different insights into social sciences and it may help us to understand complex social issues (Pavaloiu et al., 2017). Particularly in tourism context, this kind of an insight may provide useful perspectives to crises and chaotic situations such as global pandemics or disasters (Ritchie, 2004). On the other hand, this study may affect future research trends and career development of individual researchers (Law et al., 2010). Tourism managers can also benefit from AI's abilities such as complex computing and dealing with large volume of data.

\section{LITERATURE REVIEW}

Pritchard (1969) introduced bibliometrics as the application of mathematical and statistical methods on books and other types of communications. Bibliometric methods are used to assess the impact of researchers, institutions, countries, or journals (Cunill et al., 2019) and they are useful to gain a macroscopic view of large amounts of academic literature (van Nunen et al., 2018). Bibliometric methods are powerful for assessing journal performances (Cunill et al., 2019; García-Lillo et al., 2016; Guzeller \& Celiker, 2019; Merigó et al., 2019), evaluating the progress of a specific field at a given time period (Askun \& Cizel, 2019; Dhamija \& Bag, 2020; Koseoglu et al., 2016; van Nunen et al., 2018) and especially in evaluation of international scientific influence of an agent (van Raan, 2003). Bibliometrics is used across different disciplines and it's complementary to traditional methods (Zupic \& Čater, 2015). Due to its more objective and reliable analyzes compared to other qualitative and quantitative reviewing approaches (Aria \& Cuccurullo, 2017), scholars are increasingly interested in bibliometrics as a research method. 
Koseoglu et al. (2016) classified bibliometric methods as review studies, relational techniques, and evaluative techniques. They categorized systematic reviews, meta-analyzes and qualitative approaches in review studies; citation, bibliographic, co-word, co-authorship analyzes in relational techniques; while productivity measures, impact metrics and hybrid metrics are classified as evaluative techniques. Review studies use basic statistics or qualitative methods to assess a scientific study. Relational techniques try to discover the relationships in studies such as structure of the research fields, new research themes and techniques (Güzeller \& Çeliker, 2018), whereas, evaluative techniques analyze the impact of scholarly work and compare the performance or scientific contributions of two or more individuals or groups (Benckendorff \& Zehrer, 2013).

Bibliometric methods have been used in tourism, leisure and hospitality to assess the scientific production of the field. Furthermore, these were applied in context of different subfields such as smart tourism (Johnson \& Samakovlis, 2019), gastronomy (Okumus et al., 2018), lodging industry (Köseoglu et al., 2018; Okumus et al., 2019), sustainable tourism (Ruhanen et al., 2015), rural tourism (Ruiz-Real et al., 2020), wine tourism (Sánchez et al., 2017), tourism's economic impact (Comerio \& Strozzi, 2019), social media (Leung et al., 2017), peer to peer studies (Andreu et al., 2020; Núñez-Tabales et al., 2020), psychological research on tourism (Barrios et al., 2008), and competitiveness and innovation (Teixeira \& Ferreira, 2018).

Researchers apply different types of bibliometrics in their studies. Benckendorff (2009) examined papers of Australian and New Zealand researchers published in Annals of Tourism Research and Tourism Management journals between 1994-2007 by using keyword, citation, cocitation, and network analyzes. Okumus et al. (2018) analyzed the progress of food and gastronomy in tourism field between 1976 and 2016, focusing on most productive journals and institutions, and contributions of countries to the scientific field. In another study, researchers identified the emerging themes in tourism and stated that bibliometric studies can enlighten the unknown patterns in disciplines and support future theory development (Koseoglu et al., 2016). Virani et al. (2019) examined medical tourism policies and combined bibliometrics and data visualization techniques. Another distinctive point of bibliometrics is the visualization of results, thus, the method increases the comprehension of potential readers in an emergent area and extends the research scope (Qian et al., 2019).

Since bibliometrics is applicable to all scientific areas (Sánchez et al., 2017), AI can be analyzed with this tool. In terms of AI, to the best of our 
knowledge, bibliometrics has been conducted in different disciplines except tourism and hospitality. For instance, Tran et al. (2019) conducted a research on AI in health and medicine field. They reached 27,451 published documents between 1977 and 2018 from Web of Science (WoS) database. After the year 2002, numbers of AI studies in the health and medicine field bursts exponentially due to the advances in computing and data storage capacities. Authors also visualized author and country collaborations and networks. They revealed that the highest number of papers related to AI were about robotic surgery, machine learning and artificial neural network, respectively. Niu et al. (2016) examined 22,072 publications between 1990 and 2014 without delimiting the scientific field. According to this study, computer science and engineering were the most productive fields in context of AI, but the AI subject was also used in several other scientific fields as an interdisciplinary matter. They found that, among 122 countries that participated in AI research, the most productive ones were the USA, China, UK, Spain, France, Germany, and Canada, respectively. Chinese Academy of Sciences was the most productive institution, followed by Massachusetts Institute of Technology (MIT) and Hong Kong Polytech University.

Similar to the aforementioned research, Lei \& Liu (2019) conducted a study between 2007-2016 with the keyword 'artificial intelligence' but without delimiting the scientific field. They also found USA was the most productive country in AI studies, followed by UK and Iran, respectively. They highlighted that during 10-years period 1,188 articles were published in 102 research fields. They also emphasized interdisciplinary nature of AI, with technical methods such as anfis (adaptive network based fuzzy inference systems), support vector machine (a kind of machine learning), genetic algorithm and fuzzy logic being the most utilized techniques. Besides, in terms of research fields, neural network and machine learning were the most prominent areas. In another research, Shukla et al. (2019) examined the journal of Engineering Applications of Artificial Intelligence (EAAI) between years 1988-2018 on both WoS and Scopus indexes. After 2008 the number of publications started to increase significantly. Distinctively, they divided total citations to total publications (Citations Per Paper), and they also calculated average citations received by a publication per year (Citations Per Year) as these are effective metrics to show the impact of a publication. According to Scopus data, neural networks, algorithms, genetic algorithm, artificial intelligence, expert systems, fuzzy sets, fuzzy logic were the trendiest author keywords. According to WoS, developing countries such as Iran, India, Taiwan, and Turkey were among 
the top 10 countries that contributes to the EAAI journal, albeit, China was the top contributor, followed by the USA.

Many bibliometric studies have been conducted in literature to examine the progress of AI in different scientific fields. There are some commonalities in these researches such as the prominent countries regarding scientific production and, in terms of keywords, emerging topics. Authors divide their researches into time periods to distinguish periodical emerging different themes to show $\mathrm{AI}^{\prime}$ s rapid progress after spreading into other disciplines. It is obvious that AI is commonly being studied in the fields such as engineering, computer sciences, and medical and clinical studies rather than social sciences. Hence, the current study aims to bridge this gap in the tourism and hospitality field and to provide some useful insights into AI's potential for both academia and practitioners. Furthermore, this study proposes an AI perspective into the social world's complex problems.

\section{RESEARCH METHOD}

\section{Analytical Ideology}

A research philosophy, which may be assumed as a social paradigm, represents a scientific interest and guides the entire study (Gunbayi \& Sorm, 2018). It helps to enlighten the research problems systematically by employing necessary tools and methods for research. Therefore, this research adopted a qualitative way in terms of interpretive paradigm (Gunbayi \& Sorm, 2018) based on the systematic analysis of articles on AI in tourism through bibliometric analysis using $\mathrm{R}$ programming language (Askun \& Cizel, 2020).

$\mathrm{R}$ is a free and proper program that provides open source packages, such as bibliometrix R- package specifically developed for bibliometric and scientometric studies. Since bibliometrix R-package is an effective, flexible, and adaptive tool, it is useful for the current study in performing the bibliometric analyzes (Aria \& Cuccurullo, 2017). For data visualization, ggplot2 library (http://cran.r-project.org/L and VOSviewer were used. Papers were analyzed by keywords plus, authors' keywords, and titles, while network analysis, co-citation, collaboration, co-occurrence analyzes were performed to analyze keywords. Moreover, author, country, and institution effect in context of tourism was reviewed and discussed to determine the progress of the field. In general, this study investigates the most cited papers, collaborations, co-citations, thematic analysis of the field, 
keyword co-occurrence, and most common keywords of AI in tourism studies, respectively.

Most cited papers show the prominent studies in terms of total citation, local citation, and average citation. Yearly average citation of each paper was calculated to show paper's impact. Most cited papers refer the most significant papers, but most cited papers are not always the most relevant (Merigó et al., 2019). Therefore, for assessing document quality, other analyzes are considered necessary.

On the other hand, collaboration analysis was conducted on author and institution level. Collaboration networks depict the clusters of research groups consisted of authors and institutions. These networks are distinctive characteristics of contemporary researches because scholars tend to act as members of a team rather than individual actors (Glänzel \& Schubert, 2005). Assessing author collaboration networks enlightens the way of analyzed scientific knowledge among authors and shows prominent scholars, therefore it gives important insights about the future of the field. AI collaboration network in tourism was taken from author $\times$ author adjacency matrix which counts collaborating papers.

Co-citation analysis explains groups of papers which are likely to appear together in reference lists, but which also may have something in common (Benckendorff \& Zehrer, 2013). Co-citation analysis aims to show the relationship of vast knowledge between documents. If documents are gathered through two documents, this means they're connected to each other and strength of this connection is in accordance with the number of connected documents. When two different documents compile many documents, that means there is a strong connection. It can be inferred that these documents share the same accumulation of knowledge or the same methodology (Todeschini \& Baccini, 2016).

Co-occurrence analysis visualizes network connections and keywords frequently used in different documents. Creating a co-occurrence network among keywords, title and abstract of a document enables delivering a conceptual structure regarding the subject. A more frequently used keyword is represented by a larger node in the graph. Lines indicate connections between nodes and their thickness implies the strength of the relationship. Position and color of the nodes imply different theme clusters, whilst the distance between nodes asserts inverse proportion. Shorter the distance means greater co-occurrence between keywords, longer the distance means minor co-occurrence. Hence, conducting thematic evolution analysis with keyword plus is very useful. Thematic evolution displays the 
longitudinal progress of $\mathrm{AI}$ and implies the change in time periods. It visualizes the evolution of the field and enables a smooth progressive overview of the field. Co-occurrence analysis was conducted by keywords such as in thematic analysis, but differently, co-occurrence analysis depends on author keywords. Lastly, most common author keywords occurrences clarify clusters of each keyword and their occurrences in a chart-format. Keyword occurrences refer research trends of a scientific field and may also infer possible future trends.

\section{Data Source}

This study's data were obtained from the peer-reviewed literature database Scopus. Scopus and WoS are two prominent databases for analyses, and there is still an ongoing debate upon which one is better. Both databases offer comprehensive coverage at journal, article and cited reference level (Norris \& Oppenheim, 2007). Before conducting this research, topic words and keywords were applied to both databases, and as Scopus included significantly greater number and type of documents than WoS, it was preferred. Scopus offers articles, book chapters, conference papers, reviews, notes, and letters, thus providing a broader view of scientific documents.

Since the current research is a systematic analysis, aiming to position and synthesize studies about a specific research question, it uses organized, transparent, repeatable procedures in each step of the process (Littell et al., 2008). It utilizes purposeful sampling method and criterion sampling technique that are commonly used in qualitative research methods (Palys, 2008), in which keywords are sampling criterions. To create the dataset for analysis "artificial intelligence" was searched in author keywords or in abstract, whilst, "tourism" was searched in topic or in abstract. An advanced search was conducted without limiting to year, document type or language criterions. Finally, papers published between 2003 and 2020 were downloaded from Scopus on August 15, 2020. A total of 102 papers were analyzed including 52 articles, 35 conference papers, 8 reviews, 5 book chapters, 1 note and 1 letter. A remarkable number of conference papers indicates that there is a growing interest to this field, while gathering other scientific sources ensure data diversity.

In the next step, bibliographical data (e.g., papers, authors, titles, keywords, references) were downloaded in CSV format, in line with bibliometric methods proposed by Cobo et al. (2011) and Börner et al. (2005). Figure 1 displays the rapid growth of AI studies in tourism field, especially in recent years. There were only 3 papers published in 2003, and 
until 2017 there wasn't much attention to this subject. However, after 2017 the number of studies has grown significantly (annual growth rate: $8.36 \%$ ). The advancements in computer science and the proliferation of Internet may have affected the authors' tendency on AI, albeit these advances enabled much faster reach for data.

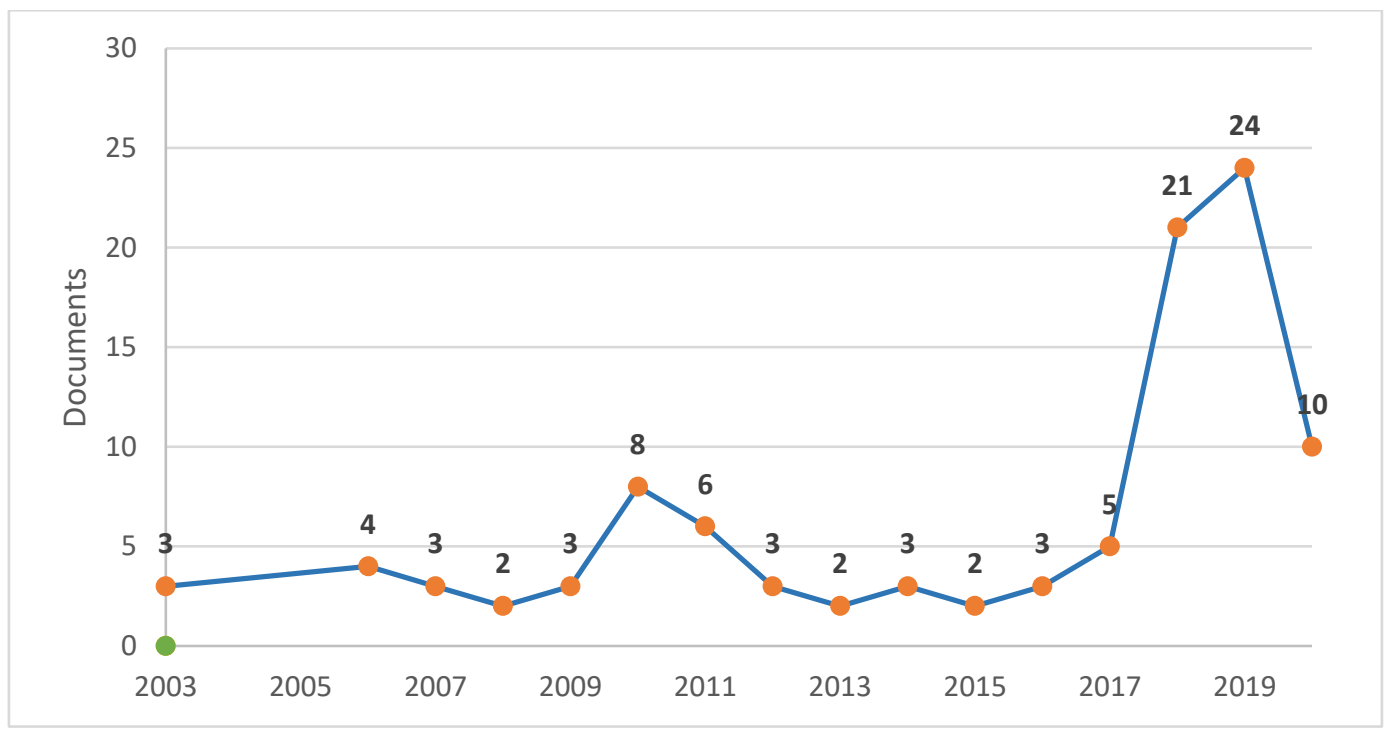

Figure 1. Annual Scientific Production

\section{RESULTS AND DISCUSSION}

Data of this research consisted of 263 authors and 102 publications, with 610 different keywords that authors used to classify their documents. Average citation per paper (16.58) and annual average citation per paper (3.04) denote that papers are highly cited and they're gaining importance gradually. Single-authored papers were conducted by 18 authors, whereas multi-authored papers were conducted by 245 authors (TAm). There are 18 single-authored papers and 84 multi-authored (TPm) ones. In that case, there is a predominant collaboration upon studies, as shown by author per paper (2.58) and co-author per paper (2.8) metrics. Because of the complex nature of interactions among authors, structure and strength of collaborations cannot be easily determined. In this case, Collaboration Index (CI) can be an effective tool to overcome that concern. CI can be calculated by a formula from Ajiferuke et al.'s (1988) study:

$$
C I=\frac{T A_{m}}{T P_{m}}=2.92
$$

Papers examined in this study (total of 102) have received 1,691 citations which means a number of 16.58 citations per paper. Total citations 
are related with the visibility of a paper, and also roughly imply the quality and impact of a study. Thus, the increasing amount of citations on open access journals' papers may provide a better interpretation to that case (Chiu \& Ho, 2007). The current study was conducted from 76 different sources, and number of 38.61 citations per paper demonstrates that, studies in tourism upon AI will gradually enhance their academic efficiency.

\section{Most Cited Papers and Collaborations}

Table 1 shows the most influential 15 papers in tourism field regarding AI. This table shows the title, total citation, local citation, and annual average citation of the papers. Akehurst's (2009) study on improving user generated content and web blogs received 218 citations and became the most cited paper, whilst, it is in the sixth place in terms of annual average citation (19.8). The paper authored by Borràs et al. (2014), which analyzed conference papers presented upon intelligent e-tourism field focusing on different types of interfaces and the usage of AI techniques, came in the second place with 214 citations, but on the fourth in annual average citation (35.7). In terms of annual average citation, on the other hand, Buhalis \& Sinarta's (2019) research upon how tourism brands' instant interaction with customers' enhances technology and social media was in first place with 56 citations within one year period. The second place was Song et al.'s (2019) research with 40 citations within one year period, upon determining the complexity of tourism demand and different forecasting methods. Buhalis et al.'s (2019) research concerning examples on information-based tourism industry's effects on intelligent settings such as AI, was in the third place with 38 citations within a year. Besides, Cho's (2003) research on forecasting the nature of tourist traffic and changes in tourism demand hits 168 citations in total, but with an annual average citation of 9.9 demonstrating that, recent studies are arousing more interest among researchers.

Figure 2 displays the AI collaboration network patterns in tourism between years 2003-2020. Leading 30 authors, collaboration of minimum one paper, and papers that show the strongest connections were taken into consideration in this analysis. Lines and their thickness indicate the presence of different collaborations. 
Table 1. Most Cited Papers

\begin{tabular}{|c|c|c|c|c|c|c|c|}
\hline & References & Journal & Title & Year & TC & LC & $\mathrm{C} / \mathrm{Y}$ \\
\hline 1 & Akehurst, G. & Service Business & $\begin{array}{l}\text { User generated content: the use of blogs for tourism } \\
\text { organisations and tourism consumers }\end{array}$ & 2009 & 218 & 3 & 19.8 \\
\hline 2 & $\begin{array}{l}\text { Borràs ,J., Moreno, } \\
\text { A., Valls, A. }\end{array}$ & $\begin{array}{l}\text { Expert Systems with } \\
\text { Applications }\end{array}$ & Intelligent tourism recommender systems: A survey & 2014 & 214 & 4 & 35.7 \\
\hline 3 & Cho, V. & Tourism Management & $\begin{array}{l}\text { A comparison of three different approaches to tourist } \\
\text { arrival forecasting }\end{array}$ & 2003 & 168 & 8 & 9.9 \\
\hline 4 & $\begin{array}{l}\text { Cambria, E. Speer, R. } \\
\text { Havasi, C., Hussain, } \\
\text { A. }\end{array}$ & $\begin{array}{l}2010 \text { AAAI Fall } \\
\text { Symposium Series }\end{array}$ & $\begin{array}{l}\text { SenticNet: A Publicly available semantic resource for } \\
\text { opinion mining }\end{array}$ & 2010 & 146 & 0 & 14.6 \\
\hline 5 & Goh, C., Law, R. & Tourism Management & $\begin{array}{l}\text { Incorporating the rough sets theory into travel demand } \\
\text { analysis }\end{array}$ & 2003 & 99 & 4 & 5.8 \\
\hline 6 & $\begin{array}{l}\text { García-Crespo, A., et } \\
\text { al. }\end{array}$ & $\begin{array}{l}\text { Expert Systems with } \\
\text { Applications }\end{array}$ & $\begin{array}{l}\text { Sem-Fit: A semantic based expert system to provide } \\
\text { recommendations in the tourism domain }\end{array}$ & 2011 & 68 & 3 & 7.6 \\
\hline 7 & Yu, G., Schwartz, Z. & $\begin{array}{l}\text { Journal of Travel } \\
\text { Research }\end{array}$ & $\begin{array}{l}\text { Forecasting short time-series tourism demand with } \\
\text { artificial intelligence models }\end{array}$ & 2006 & 56 & 7 & 4.0 \\
\hline 8 & $\begin{array}{l}\text { Buhalis, D., Sinarta, } \\
\text { Y. }\end{array}$ & $\begin{array}{l}\text { Journal of Travel \& } \\
\text { Tourism Marketing }\end{array}$ & $\begin{array}{l}\text { Real-time co-creation and nowness service: lessons from } \\
\text { tourism and hospitality }\end{array}$ & 2019 & 56 & 4 & 56.0 \\
\hline 9 & Hadavandi, E., et al. & Tourism Management & Tourist arrival forecasting by evolutionary fuzzy systems & 2011 & 54 & 3 & 6.0 \\
\hline 10 & Felfernig, A., et al. & OGAI Journal & $\begin{array}{l}\text { A short survey of recommendation technologies in travel } \\
\text { and tourism }\end{array}$ & 2006 & 49 & 1 & 3.5 \\
\hline 11 & Goh, C., Law, R. & $\begin{array}{l}\text { Journal of Travel \& } \\
\text { Tourism Marketing }\end{array}$ & $\begin{array}{l}\text { The methodological progress of tourism demand } \\
\text { forecasting: A review of related literature }\end{array}$ & 2011 & 44 & 4 & 4.9 \\
\hline 12 & $\begin{array}{l}\text { Song, H., Qiu, R.T.R., } \\
\text { Park, J. }\end{array}$ & $\begin{array}{l}\text { Annals of Tourism } \\
\text { Research }\end{array}$ & $\begin{array}{l}\text { A review of research on tourism demand forecasting: } \\
\text { Launching the Annals of Tourism Research Curated } \\
\text { Collection on tourism demand forecasting }\end{array}$ & 2019 & 40 & 0 & 40.0 \\
\hline 13 & Buhalis, D., et al.. & $\begin{array}{l}\text { Journal of Service } \\
\text { Management }\end{array}$ & $\begin{array}{l}\text { Technological disruptions in services: lessons from } \\
\text { tourism and hospitality }\end{array}$ & 2019 & 38 & 4 & 38.0 \\
\hline 14 & $\begin{array}{l}\text { Kim, K., Park, O., } \\
\text { Yun, S., Yun, H. }\end{array}$ & $\begin{array}{l}\text { Technological } \\
\text { Forecasting and Social } \\
\text { Change }\end{array}$ & $\begin{array}{l}\text { What makes tourists feel negatively about tourism } \\
\text { destinations? Application of hybrid text mining } \\
\text { methodology to smart destination management }\end{array}$ & 2017 & 31 & 1 & 10.3 \\
\hline 15 & $\begin{array}{l}\text { Lu,L., Cai, R., } \\
\text { Gursoy, D. }\end{array}$ & $\begin{array}{l}\text { International Journal } \\
\text { of Hospitality } \\
\text { Management }\end{array}$ & $\begin{array}{l}\text { Developing and validating a service robot integration } \\
\underline{\text { willingness scale }}\end{array}$ & 2019 & 26 & 3 & 26.0 \\
\hline
\end{tabular}

TC: Total citation, LC: Local citation, C/Y: Total citation/Years

Figure 2 reveals that there were 7 different author collaborations. The greatest author collaboration was consisted of Moreno, Borràs, Valls, Anton-Clavé, Flor, Isern, Russo, Pérez, and, these were in different universities of Spain. These authors' book chapter about recommender systems on geographical information systems regarding tourism destinations, and, Moreno, Borràs and Valls' article in 2014 with 214 citations influenced this primacy. In another collaboration, Buhalis from Bournemouth University, UK, published 3 different papers in 2019. Buhalis et al.'s (2019) paper with 38 citations, and Volchek et al.'s (2019) research upon tourists visiting five different London museums (13 citations) were among the influential ones. Webster from USA and Ivanov from Bulgaria 
have published four different papers since 2018 and became most productive and collaborative authors, although these papers got only 16 citations. Hadavandi and Ghanbari have collaborated in two studies. The research in ninth place at Table 1, which offers a solution regarding tourist arrival forecasting (54 citations) and the conference paper on the same topic (4 citations) affected that collaboration. Bouslama, Ayachi, and Amor from Tunusia contributed to literature by presenting two different conference papers in Spain and Serbia.

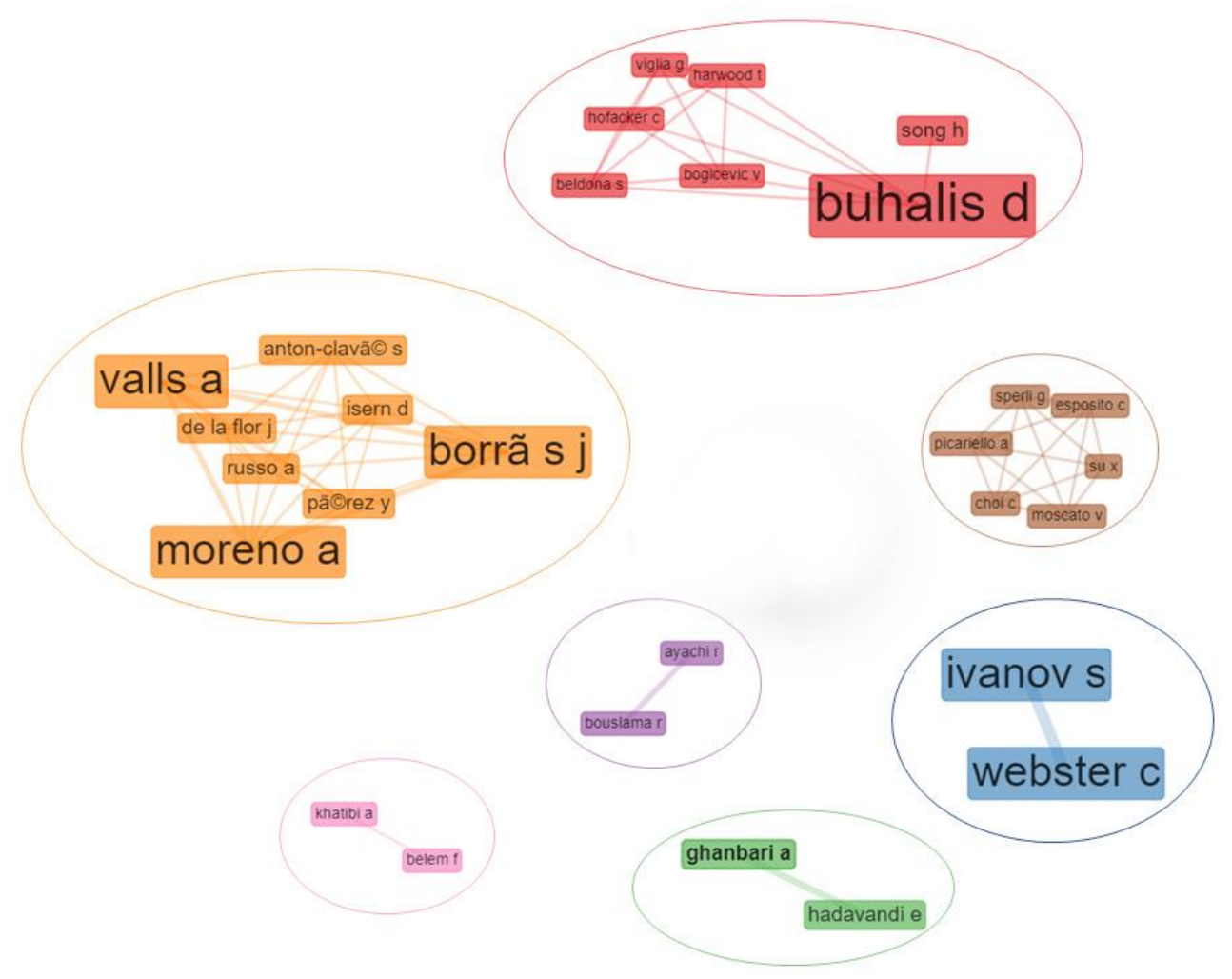

Figure 2. Author collaboration network

\section{Prominent Countries and Institutions}

In terms of institutions there are 38 different countries and the most prolific countries considering the number of papers were Spain (36), China (33), USA (24), UK (21), and Iran (14), respectively. Moreover, China (TC: 100) has got six corresponding authorships, whereas Hong Kong (TC: 320), Iran (TC: 72), Spain (TC: 294) and UK (TC: 210) got four of it. Accordingly, top 20 institutions that collaborated in at least one research were taken into consideration, and Figure 3 illustrates this collaboration among institutions (bolder line means more collaboration), likewise, total number of papers were expressed with the size of figure. There were five different collaboration groups. First of all, the research that mostly affected the collaboration of Bournemouth University (UK), De Montfort University 
(UK), The Ohio State University (USA), University of Portsmouth (UK), University of Delaware (USA), and Florida State University (USA) was the one in which Buhalis was the corresponding author. Bournemouth University (UK) from the same group has linked with another connection to University of Surrey (UK) and The Hong Kong Polytechnic University (Hong Kong) through Buhalis' research on five different London museums. The collaboration of Ball State University (USA) and Varna University of Management (Bulgaria) was due to Craig Webster and Stanislav H. Ivanov's researches. Besides, Hadavandi and Ghanbari's research affected the cooperation of the group Sharif University of Technology (Iran), University of Tehran (Iran), Iran University of Technology (Iran).

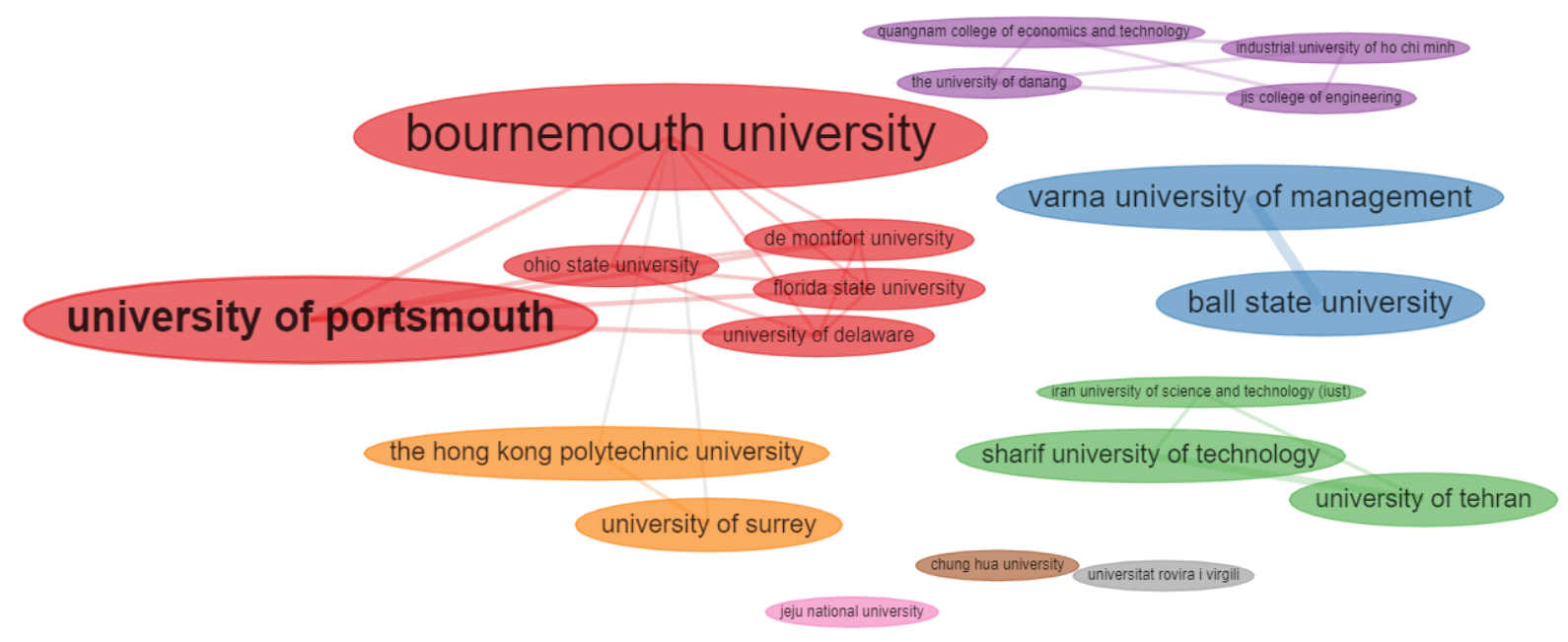

Figure 3. Institution collaboration network

\section{Co-Citation Analysis}

Figure 4 and Table 2 demonstrate the intellectual structure of AI in tourism field. Betweenness centrality (BC) in Table 2 is an advanced metrics which shows the importance of a node to create the shortcuts among other nodes, and also indicates the degree of influence of the communication between nodes (Freeman, 1977). Adapting from Guns et al. (2011) to calculate BC as follows;

$$
B C_{i}=\sum_{k=1}^{V-1} \sum_{j=k+1}^{V} \frac{P_{k j}(i)}{P_{k j}} \quad k_{\imath} j \neq i
$$

$P_{k j}$ gives the number of the shortest paths that connects $\mathrm{k}$ and $\mathrm{j}$ edges, whereas $P_{k j}(i)$ gives the number of the shortest paths passes through i edge. $V$, is the number of edges in the graph. 


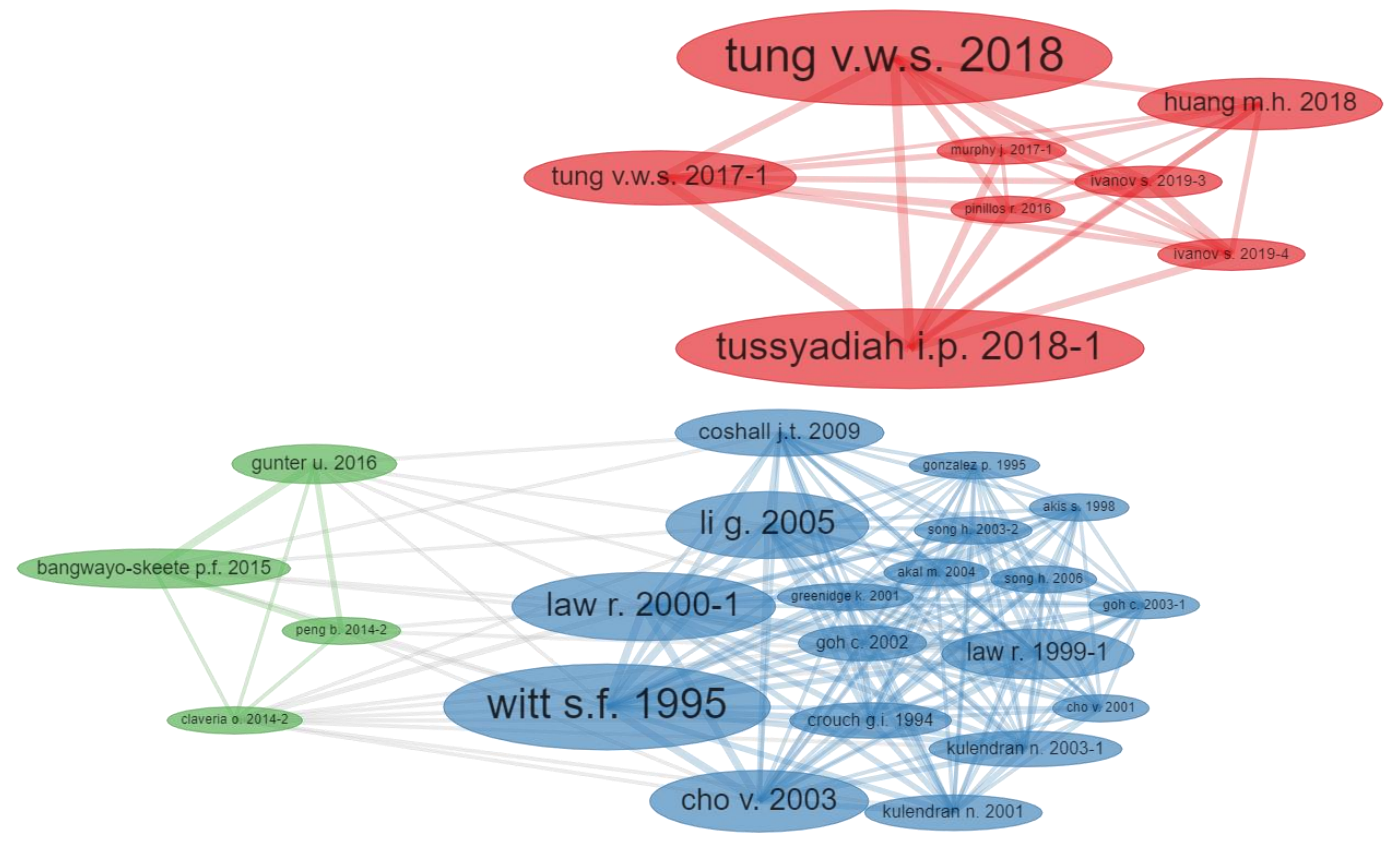

Figure 4. Co-citation paper network

Table 2. Co-citation paper network overview

\begin{tabular}{|c|c|c|c|c|c|c|}
\hline $\mathrm{Cl}$ & References & Title & Year & BC & C & $\mathrm{C} / \mathrm{Y}$ \\
\hline B & $\begin{array}{l}\text { Witt, S. F., Witt, } \\
\text { C. A. }\end{array}$ & $\begin{array}{l}\text { Forecasting tourism demand: A review of } \\
\text { empirical research }\end{array}$ & 1995 & 32.71 & 1,118 & 44,72 \\
\hline B & Law, R. & $\begin{array}{l}\text { Back-propagation learning in improving the } \\
\text { accuracy of neural network-based tourism } \\
\text { demand forecasting }\end{array}$ & 2000 & 20.36 & 407 & 20,35 \\
\hline B & Cho, V. & $\begin{array}{l}\text { A comparison of three different approaches to } \\
\text { tourist arrival forecasting }\end{array}$ & 2003 & 13.00 & 434 & 25,52 \\
\hline B & $\begin{array}{l}\text { Li, G., Song, H., } \\
\text { Witt, S.F. }\end{array}$ & $\begin{array}{l}\text { Recent developments in econometric modeling } \\
\text { and forecasting }\end{array}$ & 2005 & 7.93 & 531 & 35,40 \\
\hline $\mathrm{R}$ & $\begin{array}{l}\text { Tussyadiah, I. P, } \\
\text { Park, S. }\end{array}$ & Consumer evaluation of hotel service robots & 2018 & 1.66 & 74 & 37,00 \\
\hline G & $\begin{array}{l}\text { Bangwayo-Skeete } \\
\text { P. F., Skeete, R. } \\
\text { W. }\end{array}$ & $\begin{array}{l}\text { Can Google data improve the forecasting } \\
\text { performance of tourist arrivals? Mixed-data } \\
\text { sampling approach }\end{array}$ & 2015 & 1.5 & 200 & 40,00 \\
\hline G & $\begin{array}{l}\text { Gunter, U., } \\
\text { Önder, I. }\end{array}$ & Forecasting city arrivals with Google Analytics & 2016 & 1.5 & 72 & 18,00 \\
\hline $\mathrm{R}$ & $\begin{array}{l}\text { Tung, V. W. S. T., } \\
\text { Au, N. }\end{array}$ & $\begin{array}{l}\text { Exploring customer experiences with robotics in } \\
\text { hospitality }\end{array}$ & 2018 & 1.33 & 65 & 32,50 \\
\hline $\mathrm{R}$ & $\begin{array}{l}\text { Tung, V. W. S. T., } \\
\text { Law, R. }\end{array}$ & $\begin{array}{l}\text { The potential for tourism and hospitality } \\
\text { experience research in human-robot interactions }\end{array}$ & 2017 & 0.61 & 94 & 31,33 \\
\hline $\mathrm{R}$ & $\begin{array}{l}\text { Huang, M., Rust, } \\
\text { R. T. }\end{array}$ & Artificial intelligence in service & 2018 & 0.39 & 343 & 171,5 \\
\hline
\end{tabular}

Cl: cluster, BC: betweenness centrality, C: citation, B:blue, R:red, G:green 
Hereunder Witt and Witt's research upon forecasting tourism demand through empirical data was the most prominent research with total 1,118 citations and also got the most powerful BC degree (32.71). In the same group set, Law's study implying the importance of neural networks in tourism demand forecasting came in the second place in terms of BC (20.36) and received 407 citations. In the red group set, studies were conducted after 2017 and research topics were directly upon artificial intelligence, robotics. Huang and Rust's theoretical research received 343 citations in a short period of time, and this particularly implies that this research will be efficient in the field. In the green group set, there were studies upon forecasting tourist behavior through utilizing data sources such as Google, and co-citation researches were mainly upon forecasting.

\section{Thematic and co-occurrence Analysis}

Figure 5 shows a thematic evolution of two different periods. This progressive illustration is derived from the breakthrough in 2018 (Figure 1). There were 68 documents analyzed in 2003-2018 period, whereas 34 documents in 2019-2020. Themes are more likely to occur in four areas in a period of more than a year, thus, interpretation is required due to the high number of publications after this sudden breakthrough. First period's keyword plus number was 478 but second period's was 178. Among these keywords to filter the most frequently used ones, minimum 3 occurrence threshold were preferred. According to Cahlik's (2000) specification, concepts emerged at top-right side of the chart are defined as motor themes, and they're highly centralized and intense. In other word, these concepts imply importance for the research field and they simply illustrate the progress. In period of 2003-2018 forecasting theme's sub-dimensions were tourism demand, fuzzy systems, fuzzy inference and time series analysis, whereas expert systems theme's sub-dimensions were intelligent agents and semantics. In 2019-2020 period the emerging theme was Big Data.

The concepts in the bottom-right are highly centralized with low density, and they're called as basic and transversal themes. Besides implying importance for the field, these concepts are in relation to the common themes that interact with different fields of knowledge. In the period 20032018, under the theme of artificial intelligence, emerging sub-dimensions were knowledge management, semantic web, e-tourism, www; whereas under recommender systems theme, electronic commerce, knowledgebased systems, and intelligent systems emerged. In period of 2019-2020 there were no emerging themes in same theme zone. 

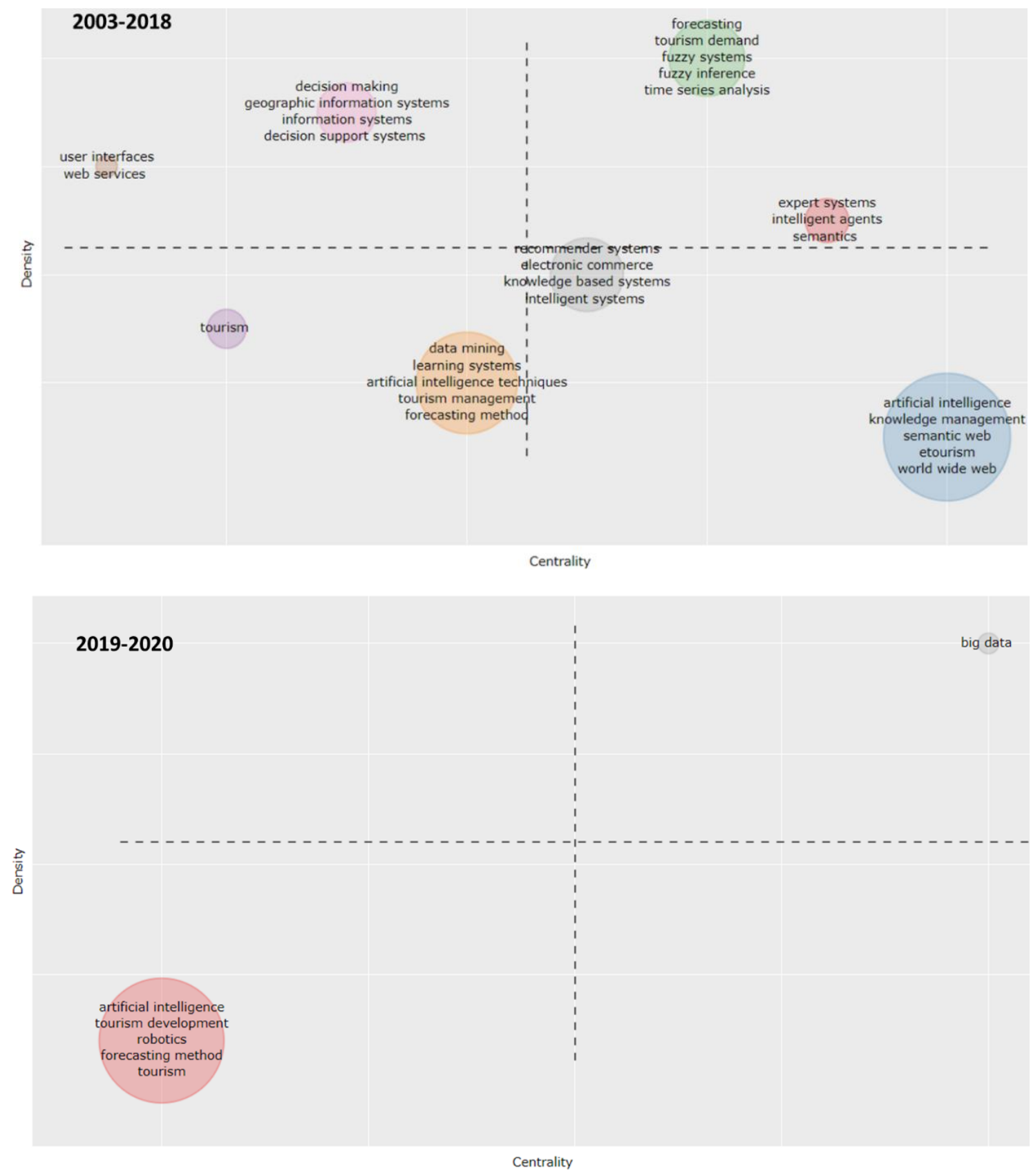

Figure 5. Thematic Evolution

Concepts emerging in the bottom-left have low centrality and low density, and they are called emerging or declining themes. These concepts are considered as underdeveloped and marginal. In 2003-2018 period, tourism and data mining themes appeared, and the emerging sub-themes of data mining were learning systems, artificial intelligence techniques, tourism management, and forecasting method. In 2019-2020 period artificial intelligence theme emerged with tourism development, robotics, forecasting method, tourism as its sub-themes. Regarding this period, themes showed up in a relatively shorter time period. It is considered 
beneficial to evaluate these emerging themes as influencers of prospective studies, and how they will change or transform with future studies. The 2019-2020 Thematic Evolution map signifies a breakthrough in terms of AI's effect on tourism, and because of its themes are highly mentioned in the scientific field, it can be interpreted that these are industry's primary contemporary demands from AI technologies.

Concepts emerging at the top-left side have low centrality but high density, and they are called high developed and isolated themes. These notions constitute highly developed and isolated themes, thus have limited importance for the research field. User interfaces and decision-making were emerging themes in 2003-2018 period. User interfaces theme's subdimension was web services, whereas geographic information systems, information systems, decision support systems were the sub-dimensions of decision-making theme. In the period of 2019-2020, there was no emerging theme in that zone. Mostly, up to the year 2018 forecasting and expert systems themes were boosting themes, but after 2019 Big Data took that place. Similarly, until 2018 artificial intelligence theme was dominant in tourism field, additionally demonstrated a strong cooperation with other fields of study. After 2019 artificial intelligence theme and its sub-themes displayed weak progress against Big Data. In this context AI's effect on tourism may gain progress regarding its collaboration with Big Data. Finally, the researchers interested in tourism, AI, and data mining themes between 2003-2018 also showed interest to AI in 2019-2020 period.

Presented as in Figure 6 the result of the analysis was consisted of six clusters. Inherently, artificial intelligence keyword had the greatest number of nodes (27). Secondly, tourism keyword in green cluster was formed by 13 nodes. Table 3 details prominent 30 author keywords in documents, demonstrating the interactions between keywords and clusters. 
VOSviewer

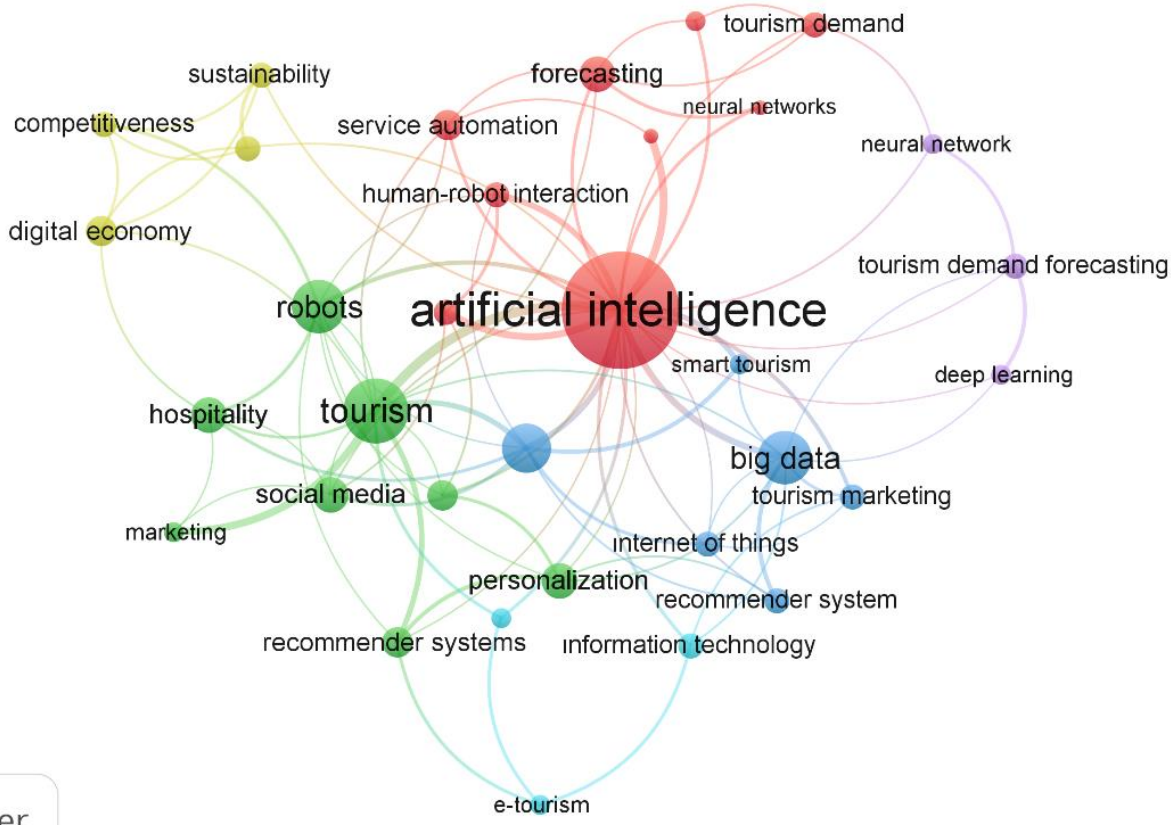

Figure 6. Co-occurrence author keywords network analysis.

(Note: Visualization was produced in VOSviewer software. Size of a node is proportional to number of appearances of the keyword, that is, larger the size, higher the occurrence of the papers in authors' keywords. The general distance between the nodes provide information about their relationship to each other. The shorter distance between nodes, the stronger their relationship. The relevance of terms is determined by counting the number of times terms occur in keywords. Colors are used to distinguish different clusters.)

Table 3. Most common keyword occurrences

\begin{tabular}{|c|c|c|c|c|c|c|c|c|c|}
\hline $\mathbf{R}$ & Keywords & $\mathrm{C}$ & Co & Oc & $\mathbf{R}$ & Keywords & $\mathrm{C}$ & Co & Oc \\
\hline 1 & artificial intelligence & 1 & 27 & 46 & 16 & human-robot interaction & 1 & 4 & 4 \\
\hline 2 & tourism & 2 & 13 & 26 & 17 & recommender system & 3 & 4 & 4 \\
\hline 3 & robots & 2 & 10 & 6 & 18 & tourism marketing & 3 & 4 & 3 \\
\hline 4 & big data & 3 & 10 & 8 & 19 & internet of things & 3 & 4 & 3 \\
\hline 5 & machine learning & 3 & 9 & 13 & 20 & competitiveness & 4 & 4 & 3 \\
\hline 6 & forecasting & 1 & 6 & 6 & 21 & overtourism & 4 & 4 & 3 \\
\hline 7 & social media & 2 & 6 & 3 & 22 & sustainability & 4 & 4 & 3 \\
\hline 8 & hospitality & 2 & 6 & 4 & 23 & tourism demand forecasting & 5 & 4 & 4 \\
\hline 9 & personalization & 2 & 6 & 4 & 24 & information technology & 6 & 4 & 4 \\
\hline 10 & service automation & 1 & 5 & 3 & 25 & review & 1 & 3 & 3 \\
\hline 11 & recommender systems & 2 & 5 & 6 & 26 & marketing & 2 & 3 & 4 \\
\hline 12 & automation & 2 & 5 & 3 & 27 & smart tourism & 3 & 3 & 8 \\
\hline 13 & digital economy & 4 & 5 & 3 & 28 & neural network & 5 & 3 & 3 \\
\hline 14 & tourism demand & 1 & 4 & 5 & 29 & deep learning & 5 & 3 & 3 \\
\hline 15 & robotics & 1 & 4 & 6 & 30 & e-tourism & 6 & 3 & 5 \\
\hline
\end{tabular}

R: rank, C: cluster, Co: Author keyword co-occurrences links, Oc: Author keyword occurrences 


\section{CONCLUSION}

This bibliometric research provides a systematic overview of AI in tourism studies. It highlights the scientific proliferation of AI by scanning the most popular papers, collaborations, research hotspots, and advancements. To the best of the authors' knowledge, this current research is among the first to evaluate and demonstrate the progress of AI in the context of tourism. Therefore, this study fills this gap by enlightening the prominent aspects of AI. As AI had a long journey since it was conceptualized by McCarthy et al. in 1955, it can be said that it has just completed its incubation period and that it is now ready to transform the society as a game-changer.

This study focuses on AI's evolution in tourism field, but more importantly, aims to draw attention to its potential effects on social sciences. Even though AI is still regarded as a complicated subject, its roots are embedded in early mathematics, economics, philosophy, and psychology (Russell \& Norvig, 2016). Therefore AI should not be evaluated as mere mathematical equations regarding computer and data science, but also as an economic and societal contribution to humankind (Pavaloiu et al., 2017; Tussyadiah \& Miller, 2019). Results of the current study concerning popular keyword occurrences, support this reflection as there were both numeral (digital economy, forecasting, big data, etc.) and human-driven (recommender systems, sustainability, personalization, etc.) keywords regarding AI.

Due to its interdisciplinary nature, adoption of AI has potential to drive innovation across sectors and provide social welfare for countries around the world (Perrault et al., 2019). According to McKinsey Global's report (Chui et al., 2018), in terms of tourism industry, AI can double what is achievable using a traditional analytic method(s) and enable a growth between $7 \%$ to $11.6 \%$ of total revenue, making tourism and travel industry the biggest potential beneficiary of $\mathrm{AI}$ among industries. Besides, this study's results upon most cited papers and co-citation networks demonstrate that, $\mathrm{AI}$ is predominantly being used for forecasting, demand analysis, and recommender systems. In addition to that, tourism industry benefits from AI in different settings such as sentiment analysis with Natural Language Processing, augmented reality, virtual reality, robotics in hospitality and service, intelligent chatbots etc. AI improves personalization and accurate recommendations in tourism which is related to main goals of the industry (Mich, 2020). However, businesses and industries come across some challenges adopting AI. IBM and O'Reilly's 
Report (Thomas, 2019) underlined these challenges and classified them in five themes as follows:

Lack of Understanding: Businesses should carefully analyze their needs and problems. They should check the applicability of AI to their concern. Because of its spreading popularity, there is a misperception that AI will fix any kind of problem.

Getting a Handle on Data: Lack of data, too much data or bad data are constraints for businesses in integrating their workflow to AI. For implementing AI successfully there is a strict need to accurate and good data.

Lack of Relevant Skills: Skills needed for AI experts are utterly different than current software engineers. This is a continuous relearning process as the machine learning algorithm learns from the training data. There is also a need for skilled AI programmers.

Trust: AI recommendations or decisions should be traceable in order to ensure businesses to see what their $\mathrm{AI}$ is doing. In doing so, businesses can avoid the risks of bias. Transparency in process is also another requirement for ethical AI.

Culture and Business Model Change: As AI enables deduction from unstructured vast amount of data, businesses should adapt their systems with new technologies AI brings in.

To overcome these challenges, IBM and O'Reilly (Thomas, 2019) propose a guiding strategy, called the AI Ladder, which suggests operationalizing AI throughout the business (infuse), building and scaling AI with trust and transparency (analyze), creating a business-ready analytics foundation (organize), making data simple and accessible (collect). Similarly, Samara et al. (2020) conducted a broad literature review and summarized AI challenges in tourism as; technical challenges, financial and business challenges, regulatory challenges, and socio-ethical challenges. Technical, financial, and business challenges refer to data quality and accuracy, ensuring lack of bias, and cost concerns. Regulatory issues imply the way data is collected and processed, referring to the role of governments regarding the safety and privacy of tourism businesses Big Data. Socioethical challenges are comprised of acceptance of $\mathrm{AI}$ in routine of tourism and the fear of job losses.

Briefly, these concerns regarding AI's implementation to businesses remind the progress and misperceptions of e-tourism along with 2000's. 
Just as in e-tourism, AI systems are already being used in tourism industry for a while without realizing these are reflections of AI. AI's effect on automation, rule-based jobs, and auto-tasks are inevitable. But if the industry manages AI properly, it will augment the jobs rather than eliminating them, and it will bring new opportunities and businesses altogether. Besides, interaction between AI systems and tourism and travel industry largely depends on tourism professionals' skills, thus, human workforce will remain valuable and essential in conducting a healthy AIindustry interaction (Cain et al., 2019). Moreover, developing countries may operate AI systems without having large industrial networks, and gain a competitive advantage by utilizing these in tourism context. Throughout its effect on decision-making process, AI can be useful in terms of underdeveloped and developing touristic destinations as it can assist and ease tourist decisions and recommendations.

By its very nature, tourism industry is fragile to local or global risks and complexities. These complexities can either be human-made disasters, natural catastrophes, or global epidemics such as SARS, COVID-19 viruses. Further to that, Gretzel et al. (2020) called for transformative research and argued that COVID-19 may act as a breaking point, challenging current paradigms, just as Kuhn (1962) articulated in 'The structure of scientific revolutions'. COVID-19 is changing conditions rapidly nowadays, and therefore exhibits a powerful uncertainty. For example, a very small change in one parameter (e.g., length of lockdowns, travel restrictions) might create very different outcome on many variables (Zenker \& Kock, 2020). Accordingly, Pappas (2019) asserts that because of its mostly reductionist approach, tourism and travel research paid less attention to chaos and complexity theories. In doing so, he assumes tourist decision-making processes as complex patterns, and suggests that complexity cognizance can help understanding rapidly changing dynamics. Therefore, it is suggested that AI techniques can be applied to diverse complex problems (Corchado \& Lees, 1998), herein particularly chaotic problems of tourism industry. In this study, it is suggested that AI tools (e.g., machine learning, neural networks, deep learning, natural language processing) may broaden tourism industry's perspectives to contemporary problems without the restriction of traditional methods.

However, integrating AI into tourism realm is a nuanced phenomenon. Tussyadiah (2020) points out application of AI and intelligent automation in tourism and travel industry is expected to increase in near future. Therefore, she sheds light on AI-tourism relationship and suggests a guideline for future researches: 
Designing Beneficial Artificial Intelligence: AI systems should be designed and developed to enhance tourism experiences by intelligent automation. This relationship can be considered as a mutual relationship that both parties interact due to the progress between each other. Technical issues such as privacy of tourists' personal data, eliminating bias, bugs, cyber-attacks, and other security concerns appear in designing and implementing beneficial artificial intelligence.

Facilitating Adoption: AI brings some acceptance concerns to tourism field. Tourism businesses, employees and tourists' attitude towards technology will shape this adoption, thus, barriers to adoption should be carefully understood and facilitators should be encouraged. This notion is evaluated in a broader viewpoint in Ivanov \& Webster's (2017) study. Authors discussed adoption process in scope of robots, AI, and service automation in tourism and travel industry. They focused on costs of AI and implied that company characteristics and culture, technology costs, degree of technological complexity, customer's attitudes and characteristics, and safety characteristics affect cost side of AI adoption.

Assessing the Impacts of Intelligent Automation in Tourism: Positive and negative effects of AI need to be deliberately evaluated with respect to host community, tourists, and tourism professionals, namely the industry. Dynamics of AI integrated destination and community may be rapidly changed, so the ratio of labor-automation should be carefully planned. Ethical concerns also arise in terms of human-robot interaction; thus, probable harms of intelligent systems must be minimized.

Creating a Sustainable Future: AI systems and intelligent automation should prevent prospective future problems of tourism. Along with governmental policy support, AI systems can be designed to reduce the negative effects of automation in industry; and provide a sustainable development through tourism. Since intelligent automation may diminish socialization between tourism partners (e.g., tourist, employee), beneficial AI implementation acts a vital role in maintaining human values and responsible use behaviors among partners. Regarding AI-tourism relationship, both technical and social aspects are critical to create a sustainable future.

This study aims to contribute to scientific field of AI in tourism context by providing the hotspots and progress, and furthermore highlights the importance of AI for changing tourism complexities. Focusing on its interdisciplinary characteristic, AI can be an effective tool for tourism 
stakeholders (e.g., tourist, tourism employees, destinations, governance actors) in adaption of new solutions to contemporary concerns.

Finally, this bibliometric study has some shortcomings. First, the current study was conducted on documents incorporated in Scopus database, hence, future studies could use Google Scholar as a data collection database. Second, the data source of this study was limited to only tourismrelated documents. Future research could examine the progress of AI in other fields or apply inclusive bibliometrics to different disciplines to review the evolution. Considering the limitations of bibliometrics, systematic reviews and content analyses of most cited papers can be conducted to gain deeper understanding of AI in different fields. Lastly, this study was conducted upon keywords. Therefore, conducting different bibliometric techniques in other languages could provide a valuable evaluation upon AI.

\section{REFERENCES}

Ajiferuke, I., Burell, Q., \& Tague, J. (1988). Collaborative coefficient: A single measure of the degree of collaboration in research. Scientometrics, 14(5-6), 421-433.

Akehurst, G. (2009). User generated content: The use of blogs for tourism organisations and tourism consumers. Service Business, 3(1), 51-61. https://doi.org/10.1007/s11628-008-0054-2

Andreu, L., Bigne, E., Amaro, S., \& Palomo, J. (2020). Airbnb research: an analysis in tourism and hospitality journals. International Journal of Culture, Tourism, and Hospitality Research, 14(1), 2-20. https://doi.org/10.1108/IJCTHR-06-2019-0113

Aria, M., \& Cuccurullo, C. (2017). Bibliometrix: An R-tool for comprehensive science mapping analysis. Journal of Informetrics, 11(4), 959-975. https://doi.org/10.1016/j.joi.2017.08.007

Askun, V., \& Cizel, R. (2019). Kompleks problem çözme üzerine R programı ile bir bibliyometrik analiz. Mediterranean Journal of Humanities, 9(1), 37-47. https://doi.org/10.13114/mjh.2019.445

Askun, V., \& Cizel, R. (2020). Twenty years of research on mixed methods. Journal of Mixed Methods Research, 1(1), 28-43. https://doi.org/10.14689/jomes.2020.1.2

Barrios, M., Borrego, A., Vilaginés, A., Ollé, C., \& Somoza, M. (2008). A bibliometric study of psychological research on tourism. Scientometrics, 77(3), 453-467. https://doi.org/10.1007/s11192-007-1952-0

Benckendorff, P. (2009). Themes and trends in Australian and New Zealand tourism research: A social network analysis of citations in two leading journals (1994-2007). Journal of Hospitality and Tourism Management, 16(1), 1-15. https://doi.org/10.1375/jhtm.16.1.1

Benckendorff, P., \& Zehrer, A. (2013). A network analysis of tourism research. Annals of Tourism Research, 43, 121-149. https://doi.org/10.1016/j.annals.2013.04.005

Börner, K., Chen, C., \& Boyack, K. W. (2005). Visualizing knowledge domains. Annual Review of Information Science and Technology, 37, 179-255. https://doi.org/10.1002/aris.1440370106

Borràs, J., Moreno, A., \& Valls, A. (2014). Intelligent tourism recommender systems: A 
survey. Expert Systems with Applications, 41, 7370-7389. https://doi.org/10.1016/j.eswa.2014.06.007

Bowen, J., \& Whalen, E. (2017). Trends that are changing travel and tourism. Worldwide Hospitality and Tourism Themes, 9(6), 592-602. https://doi.org/10.1108/WHATT-092017-0045

Buhalis, D. (2003). eTourism: Information technology for strategic tourism management. London: Pearson Education.

Buhalis, D., Harwood, T., Bogicevic, V., Viglia, G., Beldona, S., \& Hofacker, C. (2019). Technological disruptions in services: Lessons from tourism and hospitality. Journal of Service Management, 30(4), 484-506. https://doi.org/10.1108/JOSM-122018-0398

Buhalis, D., \& Sinarta, Y. (2019). Real-time co-creation and nowness service: Lessons from tourism and hospitality. Journal of Travel $\mathcal{E}$ Tourism Marketing, 36(5), 563-582. https://doi.org/10.1080/10548408.2019.1592059

Cahlik, T. (2000). Search for fundamental articles in economics. Scientometrics, 49(3), 389402.

Cain, L. N., Thomas, J. H., \& Alonso, M. (2019). From sci-fi to sci-fact: The state of robotics and AI in the hospitality industry. Journal of Hospitality and Tourism Technology, 10(4), 624-650. https://doi.org/10.1108/JHTT-07-2018-0066

Casteleiro-Roca, J.-L., Gomez-Gonzalez, J. F., Calvo-Rolle, J. L., Jove, E., Quintian, H., Acosta Martin, J. F., ... Mendez-Perez, J. A. (2018). Prediction of the energy demand of a hotel using an artificial intelligence-based model. In J. F. de Cos Juez, J. R. Villar, E. A. de la Cal \& A. Herrero (Eds.), Hybrid Artificial Intelligent Systems (Vol. 1, pp. 586-596). Cham: Springer. https://doi.org/10.1007/978-3-319-92639-1

Chiu, W. T., \& Ho, Y. S. (2007). Bibliometric analysis of tsunami research. Scientometrics, 73(1), 3-17. https://doi.org/10.1007/s11192-005-1523-1

Cho, V. (2003). A comparison of three different approaches to tourist arrival forecasting. Tourism Management, 24(3), 323-330. https://doi.org/10.1016/S0261-5177(02)00068-7

Chui, M., Manyika, J., Miremadi, M., Henke, N., Chung, R., Nel, P., \& Malhotra, S. (2018). Notes from the AI frontier: Insights from hundreds of use cases. In McKinsey\& Company. Retrieved September 10, 2020, from https://www.mckinsey.com/ /media/mckinsey/featured\%20insights/artificial\%20 intelligence/notes $\% 20$ from $\% 20$ the $\% 20$ ai $\% 20$ frontier $\% 20$ applications $\% 20$ and $\% 20 \mathrm{v}$ alue $\% 20$ of $\% 20$ deep $\% 20$ learning/notes-from-the-ai-frontier-insights-fromhundreds-of-use-cases-discussion-paper.ashx.

Cobo, M. J., López-Herrera, A. G., Herrera-Viedma, E., \& Herrera, F. (2011). Science mapping software tools: Review, analysis, and cooperative study among tools. Journal of the American Society for Information Science and Technology, 62(7), 13821402. https://doi.org/10.1002/asi.21525

Comerio, N., \& Strozzi, F. (2019). Tourism and its economic impact: A literature review using bibliometric tools. Tourism Economics, 25(1), 109-131. https://doi.org/10.1177/1354816618793762

Corchado, J. M., \& Lees, B. (1998). Cognitive models for integrating artificial intelligence approaches. AII Workshop on Knowledge Discovery. Glasgow, UK.

Cunill, O. M., Salvá, A. S., Gonzalez, L. O., \& Mulet-Forteza, C. (2019). Thirty-fifth anniversary of the International Journal of Hospitality Management: A bibliometric overview. International Journal of Hospitality Management, 78, 89-101. https://doi.org/10.1016/j.ijhm.2018.10.013

Dhamija, P., \& Bag, S. (2020). Role of artificial intelligence in operations environment: A 
review and bibliometric analysis. TQM Journal, 32(4), 869-896. https://doi.org/10.1108/TQM-10-2019-0243

Ferràs, X., Hitchen, E. L., Tarrats-Pons, E., \& Arimany-Serrat, N. (2020). Smart tourism empowered by artificial intelligence: The case of Lanzarote. Journal of Cases on Information Technology, 22(1), 1-13. https://doi.org/10.4018/JCIT.2020010101

Freeman, L. C. (1977). A set of measures of centrality based on betweenness. Sociometry, 40(1), 35- 41. https://doi.org/10.2307/3033543

Gajdošík, T., \& Marciš, M. (2019). Artificial intelligence tools for smart tourism development. In R. Silhavy (Ed.), Artificial Intelligence Methods in Intelligent Algorithms (Vol. 985, pp. 392-402). Cham: Springer. https://doi.org/10.1007/978-3030-19810-7_39

García-Lillo, F., Úbeda-García, M., \& Marco-Lajara, B. (2016). The intellectual structure of research in hospitality management: A literature review using bibliometric methods of the journal International Journal of Hospitality Management. International Journal of Hospitality Management, 52, 121-130. https://doi.org/10.1016/j.ijhm.2015.10.007

Glänzel, W., \& Schubert, A. (2005). Analysing scientifc networks through co-authorship. In H. F. Moed, W. Glänzel, \& U. Schmoch (Eds.), Handbook of quantitative science and technology research (pp. 257-276). Berlin: Springer.

González-Rodríguez, M. R., Díaz-Fernández, M. C., \& Pacheco Gómez, C. (2020). Facialexpression recognition: An emergent approach to the measurement of tourist satisfaction through emotions. Telematics and Informatics, 51. https://doi.org/10.1016/j.tele.2020.101404

Gretzel, U. (2011). Intelligent systems in tourism. A social science perspective. Annals of Tourism Research, 38(3), 757-779. https://doi.org/10.1016/j.annals.2011.04.014

Gretzel, U., Fesenmaier, D. R., \& O'Leary, J. T. (2006). The transformation of consumer behaviour. In D. Buhalis \& C. Costa (Eds.), Tourism Business Frontiers: Consumers, Products and Industry (pp. 9-18). Oxford: Elsevier. https://doi.org/10.1016/b978-07506-6377-9.50009-2

Gretzel, U., Fuchs, M., Baggio, R., Hoepken, W., Law, R., Neidhardt, J., ... Xiang, Z. (2020). e-Tourism beyond COVID-19: a call for transformative research. Information Technology and Tourism, 22(2), 187-203. https://doi.org/10.1007/s40558-020-00181-3

Gunbayi, I., \& Sorm, S. (2018). Social paradigms in guiding social research design: The functional, interpretive, radical humanist and radical structural paradigms. International Journal on New Trends in Education and Their Implications, 9(2), 57-76.

Guns, R., Liu, Y. X., \& Mahbuba, D. (2011). Q-measures and betweenness centrality in a collaboration network: A case study of the field of informetrics. Scientometrics, 87(1), 133-147. https://doi.org/10.1007/s11192-010-0332-3

Guzeller, C. O., \& Celiker, N. (2019). Bibliometrical analysis of Asia Pacific Journal of Tourism Research. Asia Pacific Journal of Tourism Research, 24(1), 108-120. https://doi.org/10.1080/10941665.2018.1541182

Güzeller, C. O., \& Çeliker, N. (2018). Bibliometric analysis of tourism research for the period 2007-2016. Advances in Hospitality and Tourism Research, 6(1), 1-22. https://doi.org/10.30519/ahtr.446248

Hadavandi, E., Ghanbari, A., Shahanaghi, K., \& Abbasian-Naghneh, S. (2011). Tourist arrival forecasting by evolutionary fuzzy systems. Tourism Management, 32(5), 1196-1203. https://doi.org/10.1016/j.tourman.2010.09.015

Inanc-Demir, M., \& Kozak, M. (2019). Big data and its supporting elements: implications for tourism and hospitality marketing. In M. Sigala, R. Rahimi, \& M. Thelwall 
(Eds.), Big Data and Innovation in Tourism, Travel, and Hospitality: Managerial Approaches, Techniques, and Applications (pp. 213-223). Singapore: Springer. https://doi.org/10.1007/978-981-13-6339-9

Ivanov, S., \& Webster, C. (2017). Adoption of robots, artificial intelligence and service automation by travel, tourism and hospitality companies - a cost-benefit analysis. In V. Marinov, M. Vodenska, M. Assenova \& E. Dogramadjieva (Eds.) Traditions and Innovations in Contemporary Tourism (pp. 190-203). UK: Cambridge Scholars Publishing.

Johnson, A. G., \& Samakovlis, I. (2019). A bibliometric analysis of knowledge development in smart tourism research. Journal of Hospitality and Tourism Technology, 10(4), 600623. https://doi.org/10.1108/JHTT-07-2018-0065

Kazak, A. N., Chetyrbok, P. V., \& Oleinikov, N. N. (2020). Artificial intelligence in the tourism sphere. IOP Conference Series: Earth and Environmental Science, 421(4). https://doi.org/10.1088/1755-1315/421/4/042020

Kirilenko, A. P., Stepchenkova, S. O., Kim, H., \& Li, X. (Robert). (2018). Automated sentiment analysis in tourism: Comparison of approaches. Journal of Travel Research, 57(8), 1012-1025. https://doi.org/10.1177/0047287517729757

Köseoglu, M. A., Okumus, F., Putra, E. D., Yildiz, M., \& Dogan, I. C. (2018). Authorship trends, collaboration patterns, and co-authorship networks in lodging studies (1990-2016). Journal of Hospitality Marketing and Management, 27(5), 561-582. https://doi.org/10.1080/19368623.2018.1399192

Koseoglu, M. A., Rahimi, R., Okumus, F., \& Liu, J. (2016). Bibliometric studies in tourism. Annals of Tourism Research, 61, 180-198. https://doi.org/10.1016/j.annals.2016.10.006

Kuhn, T. S. (1962). The structure of scientific revolutions. Chicago: University of Chicago press.

Law, R. (1998). Room occupancy rate forecasting: A neural network approach. International Journal of Contemporary Hospitality Management, 10(6), 234-239. https://doi.org/10.1108/09596119810232301

Law, R. (2000). Back-propagation learning in improving the accuracy of neural networkbased tourism demand forecasting. Tourism Management, 21(4), 331-340. https://doi.org/10.1016/S0261-5177(99)00067-9

Law, R., Leung, R., \& Buhalis, D. (2010). An analysis of academic leadership in hospitality and tourism journals. Journal of Hospitality and Tourism Research, 34(4), 455-477. https://doi.org/10.1177/1096348010370866

Lei, Y., \& Liu, Z. (2019). The development of artificial intelligence: A bibliometric analysis, 2007-2016. Journal of Physics: Conference Series, 1168(2). https://doi.org/10.1088/17426596/1168/2/022027

Leung, X. Y., Sun, J., \& Bai, B. (2017). Bibliometrics of social media research: A co-citation and co-word analysis. International Journal of Hospitality Management, 66, 35-45. https://doi.org/10.1016/j.ijhm.2017.06.012

Littell, J. H., Corcoran, J., \& Pillai, V. (2008). Systematic reviews and meta-analysis. New York: Oxford University Press.

McCarthy, J., Minksy, M., Rochester, L., \& Shannon, C. E. (1955). A proposal for the Dartmouth summer research project on artificial intelligence. AI magazine, 27(4), 12-12. Retrieved December 5, 2020, from http://wwwformal.stanford.edu/jmc/history/dartmouth.pdf

Merigó, J. M., Mulet-Forteza, C., Valencia, C., \& Lew, A. A. (2019). Twenty years of Tourism Geographies: A bibliometric overview. Tourism Geographies, 21(5), 881-910. https://doi.org/10.1080/14616688.2019.1666913 
Mich, L. (2020). Artificial intelligence and machine learning. In Z. Xiang, M. Fuchs, U. Gretzel, \& W. Höpken (Eds.), Handbook of e-Tourism. Springer Nature Switzerland. https://doi.org/10.1007/978-3-030-05324-6_25-1

Niu, J., Tang, W., Xu, F., Zhou, X., \& Song, Y. (2016). Global research on artificial intelligence from 1990-2014: Spatially-explicit bibliometric analysis. ISPRS International Journal of Geo-Information, 5(5), 1-19. https://doi.org/10.3390/ijgi5050066

Norris, M., \& Oppenheim, C. (2007). Comparing alternatives to the Web of Science for coverage of the social sciences' literature. Journal of Informetrics, 1(2), 161-169. https://doi.org/10.1016/j.joi.2006.12.001

Núñez-Tabales, J. M., Solano-Sánchez, M. Á., \& Caridad-y-López-del-Río, L. (2020). Ten years of Airbnb phenomenon research: A bibliometric approach (2010-2019). Sustainability, 12(15). https://doi.org/10.3390/su12156205

Okumus, B., Koseoglu, M. A., \& Ma, F. (2018). Food and gastronomy research in tourism and hospitality: A bibliometric analysis. International Journal of Hospitality Management, 73, 64-74. https://doi.org/10.1016/j.ijhm.2018.01.020

Okumus, F., Köseoglu, M. A., Putra, E. D., Dogan, I. C., \& Yildiz, M. (2019). A bibliometric analysis of lodging-context research from 1990 to 2016. Journal of Hospitality and Tourism Research, 43(2), 210-225. https://doi.org/10.1177/1096348018765321

Palys, T. (2008). Purposive sampling. In L. M. Given (Ed.), The Sage encyclopedia of qualitative research methods (pp. 697-698). California: Sage.

Pannu, A. (2015). Artificial intelligence and its application in different areas. International Journal of Engineering and Innovative Technology, 4(10), 79-84.

Pappas, N. (2019). UK outbound travel and Brexit complexity. Tourism Management, 72, $12-$ 22. https://doi.org/10.1016/j.tourman.2018.11.004

Pavaloiu, A., Köse, U., \& Boz, H. (2017). How to apply artificial intelligence in social sciences. IASOS - Congress of International Applied Social Sciences, (September). Uşak, Turkey. Retrieved September 10, 2020, from https://www.researchgate.net/publication/325398286_How_to_Apply_Artificial_I ntelligence_in_Social_Sciences

Perrault, R., Shoham, Y., Brynjolfsson, E., Clark, J., Etchemendy, J., Grosz Harvard, B., ... Mishra, S. (2019). The AI Index 2019 Annual Report. In AI Index Steering Committee, Human-Centered AI Institute. Stanford. Retrieved September 10, 2020, from https://hai.stanford.edu/sites/g/files/sbiybj10986/f/ai_index_2019_report.pdf

Pritchard, A. (1969). Statistical bibliography or bibliometrics. Journal of Documentation, 25(4), 348-349.

Qian, J., Law, R., \& Wei, J. (2019). Knowledge mapping in travel website studies: A scientometric review. Scandinavian Journal of Hospitality and Tourism, 19(2), 192-209. https://doi.org/10.1080/15022250.2018.1526113

Ritchie, B. W. (2004). Chaos, crises and disasters: A strategic approach to crisis management in the tourism industry. Tourism Management, 25(6), 669-683. https://doi.org/10.1016/j.tourman.2003.09.004

Ruhanen, L., Weiler, B., Moyle, B. D., \& McLennan, C. J. (2015). Trends and patterns in sustainable tourism research: A 25-year bibliometric analysis. Journal of Sustainable Tourism, 23(4), 517-535. https://doi.org/10.1080/09669582.2014.978790

Ruiz-Real, J. L., Uribe-Toril, J., Valenciano, J. de P., \& Gázquez-Abad, J. C. (2020). Rural tourism and development: Evolution in scientific literature and trends. Journal of Hospitality and Tourism Research, 1-25. https://doi.org/10.1177/1096348020926538

Russell, S. J., \& Norvig, P. (2016). Artificial intelligence: A modern approach (3rd ed.). Harlow: 
Pearson Education.

Samara, D., Magnisalis, I., \& Peristeras, V. (2020). Artificial intelligence and big data in tourism: A systematic literature review. Journal of Hospitality and Tourism Technology, 11(2), 343-367. https://doi.org/10.1108/JHTT-12-2018-0118

Sánchez, A. D., de la Cruz Del Río Rama, M., \& García, J. Á. (2017). Bibliometric analysis of publications on wine tourism in the databases Scopus and WoS. European Research on Management and Business Economics, 23(1), 8-15. https://doi.org/10.1016/j.iedeen.2016.02.001

Shukla, A. K., Janmaijaya, M., Abraham, A., \& Muhuri, P. K. (2019). Engineering applications of artificial intelligence: A bibliometric analysis of 30 years (19882018). Engineering Applications of Artificial Intelligence, 85, 517-532. https://doi.org/10.1016/j.engappai.2019.06.010

Singh, S. K., Rathore, S., \& Park, J. H. (2020). BlockIoTIntelligence: A blockchain-enabled intelligent IoT architecture with artificial intelligence. Future Generation Computer Systems, 110, 721-743. https://doi.org/10.1016/j.future.2019.09.002

Song, H., Qiu, R. T. R., \& Park, J. (2019). A review of research on tourism demand forecasting. Annals of Tourism Research, 75, 338-362. https://doi.org/10.1016/j.annals.2018.12.001

Teixeira, S. J., \& Ferreira, J. J. D. M. (2018). A bibliometric study of regional competitiveness and tourism innovation. International Journal of Tourism Policy, 8(3), 214-243. https://doi.org/10.1504/IJTP.2018.094483

Thomas, R. (2019). The AI ladder: Demystifying AI challenges. In: IBM and O'Reilly. Retrieved September 10, 2020, from https://www.oreilly.com/onlinelearning/report/The-AI-Ladder.pdf.

Todeschini, R., \& Baccini, A. (2016). Handbook of bibliometric indicators: Quantitative tools for studying and evaluating research. Weinheim, Germany: Wiley-VCH.

Topal, I., \& Uçar, M. K. (2018). In tourism, using artificial intelligence forecasting with Tripadvisor data: Year of Turkey in China. International Conference on Artificial Intelligence and Data Processing (IDAP), 1-5. Retrieved February 15, 2020, from https://ieeexplore.ieee.org/stamp/stamp.jsp?arnumber $=8620874$

Tran, B., Vu, G., Ha, G., Vuong, Q.-H., Ho, M.-T., Vuong, T.-T., ... Ho, R. (2019). Global evolution of research in artificial intelligence in health and medicine: $\mathrm{A}$ bibliometric study. Journal of Clinical Medicine, 8(360). https://doi.org/10.3390/jcm8030360

Tussyadiah, I. (2020). A review of research into automation in tourism: Launching the Annals of Tourism Research Curated Collection on artificial intelligence and robotics in tourism. Annals of Tourism Research, 81, 102883. https://doi.org/10.1016/j.annals.2020.102883

Tussyadiah, I., \& Miller, G. (2019). Perceived impacts of artificial intelligence and responses to positive behaviour change intervention. In Information and Communication Technologies in Tourism 2019 (pp. 359-370). Springer International Publishing. https://doi.org/10.1007/978-3-030-05940-8

van Nunen, K., Li, J., Reniers, G., \& Ponnet, K. (2018). Bibliometric analysis of safety culture research. Safety Science, 108, 248-258. https://doi.org/10.1016/j.ssci.2017.08.011

van Raan, A. F. J. (2003). The use of bibliometric analysis in research performance assessment and monitoring of interdisciplinary scientific developments. TATuP Zeitschrift Für Technikfolgenabschätzung in Theorie Und Praxis, 12(1), 20-29. https://doi.org/10.14512/tatup.12.1.20

Virani, A., Wellstead, A., \& Howlett, M. P. (2019). Where is the policy? A bibliometric 
review of the state of policy research on medical tourism. Global Health Research and Policy, 5, 1-16. https://doi.org/10.2139/ssrn.3445235

Volchek, K., Liu, A., Song, H., \& Buhalis, D. (2019). Forecasting tourist arrivals at attractions: Search engine empowered methodologies. Tourism Economics, 25(3), 425-447. https://doi.org/10.1177\%2F1354816618811558

Zenker, S., \& Kock, F. (2020). The coronavirus pandemic-A critical discussion of a tourism research agenda. Tourism Management, 81, 104164. https://doi.org/10.1016/j.tourman.2020.104164

Zhang, B., Li, N., Shi, F., \& Law, R. (2020). A deep learning approach for daily tourist flow forecasting with consumer search data. Asia Pacific Journal of Tourism Research, 25(3), 323-339. https://doi.org/10.1080/10941665.2019.1709876

Zheng, W., Liao, Z., \& Lin, Z. (2020). Navigating through the complex transport system: A heuristic approach for city tourism recommendation. Tourism Management, 81, 104162. https://doi.org/10.1016/j.tourman.2020.104162

Zlatanov, S., \& Popesku, J. (2019). Current applications of artificial intelligence in tourism and hospitality. In International Scientific Conference on Information Technology and Data Related Research (pp. 84-90), Sinteza, Romania.

Zupic, I., \& Čater, T. (2015). Bibliometric methods in management and organization. Organizational Research Methods, 18(3), 429-472. https://doi.org/10.1177/1094428114562629 